\title{
Clinical Presentation and Management of Eyes with Globe Perforation during Peribulbar and Retrobulbar Anesthesia: A Retrospective Case Series
}

\author{
Naresh Babu, Jayant Kumar, Piyush Kohli, Ashish Ahuja, Prerana Shah, Kim Ramasamy \\ Department of Vitreo-retinal Services, Aravind Eye Hospital and Post Graduate Institute of Ophthalmology, Madurai, India
}

\begin{abstract}
Purpose: To evaluate the clinical presentation, management, and outcome of eyes with an inadvertent globe perforation during peribulbar or retrobulbar block.

Methods: This retrospective study evaluated the eyes which had an accidental globe perforation during local ocular anesthesia from 2012 to 2020. The patients were divided into three groups: group 1, Clear media with no rhegmatogenous retinal detachment (RRD); group 2, significant vitreous hemorrhage (VH) precluding the retinal view without RRD; and group 3, RRD with/without VH.

Results: Twenty-five patients were included in the study. The mean axial length (AL) was $24.7 \pm 2.7 \mathrm{~mm}$ (range, 20.9-31.2 $\mathrm{mm})$. The most common presenting feature was $\mathrm{VH}(\mathrm{n}=14)$. The treatment included retinal laser barrage $(n=7)$ and vitrecto$m y(n=17)$. Retinal breaks were identified in all the eyes (total breaks $=37)$. The mean presenting best-corrected visual acuity in groups 1,2 , and 3 were logarithm of the minimum angle of resolution $0.79 \pm 0.73,1.82 \pm 0.78$, and $2.13 \pm 0.59$ respectively. All the treated patients had an attached retina at the last follow-up. The mean final best-corrected visual acuity for each group was logarithm of the minimum angle of resolution $0.59 \pm 0.79,0.48 \pm 0.26$, and $1.25 \pm 0.64$, respectively $(p=0.006)$. The development of RRD was associated with a larger $\operatorname{AL}(p=0.015)$; while the development of significant $\mathrm{VH}$ associated with the superior location of the perforation $(p=0.015)$, late recognition of the perforation $(p=0.004)$, and multiple perforations $(p$ $=0.015)$.

Conclusions: Early recognition and intervention in eyes with an inadvertent perforation can lead to a good outcome. Eyes with a longer AL, superior, and multiple perforations are at higher risk of developing complications like RRD and VH. Complications like RRD, macular injury, and vascular occlusion are risk factors for poor prognosis.
\end{abstract}

Key Words: Local anesthesia, Perforation, Peribulbar block, Retinal detachment, Retinal perforations

Received: June 11, 2021 Final revision: October 15, 2021 Accepted: October 24, 2021

Corresponding Author: Piyush Kohli, MS. Department of Vitreo-retinal Services, Aravind Eye Hospital and Post Graduate Institute of Ophthalmology, 1, Anna Nagar, Madurai 625020, Tamil Nadu, India. Tel: 919888-481882, Fax: 91-0452-4356100, E-mail: piyush@aravind.org
The akinesia required for performing ocular surgeries is usually achieved with the help of local anesthesia, which can be administered using techniques like retrobulbar, peribulbar, and subtenon block. All these methods are highly effective. However, all these procedures are blind and can lead to an inadvertent globe perforation [1-3]. 
The reported incidence of an accidental globe perforation after retrobulbar or peribulbar block is around $0.006 \%$ to $0.13 \%[1,2,4-6]$. Such a perforation can lead to complications like retinal break(s), subretinal hemorrhage (SRH) around the retinal break(s), vitreous hemorrhage (VH), rhegmatogenous retinal detachment (RRD), and/ or endophthalmitis [1-3]. An inadvertent injection of the anesthetic drug inside the eyeball can be even more dangerous $[7,8]$.

Most of the earlier studies related to an inadvertent globe perforation secondary to retrobulbar or peribulbar block are limited to case reports and small case series [4,5,9-18]. Also, most of these studies did not evaluate the management outcomes in eyes with this rare complication. This study was done to evaluate the clinical presentation, management, and outcome of the eyes which had an inadvertent globe perforation while injecting peribulbar or retrobulbar anesthesia. The risk factors for poor outcomes were also analyzed.

\section{Materials and Methods}

This was a retrospective study conducted at a tertiary-care eye hospital in South India. The study was conducted with the approval of the institutional review board (No. ECR/182/INST/TN/2013; April 20, 2013) and adhered to the tenets of the Declaration of Helsinki. Informed consent was taken from all the patients after explaining the nature of the disease, its treatment, and the associated complications. All the patients were treated by a single experienced surgeon (NB).

The medical records of all the patients who had an inadvertent globe perforation, while injecting peribulbar or retrobulbar anesthesia before the start of ocular surgery, from 2012 to 2020 were reviewed. Both the in-house complications as well the patients referred from outside the hospital were included in the study. The data reviewed included the patient demographics; the time of recognition of the inadvertent perforation; the axial length (AL); the presenting best-corrected visual acuity (BCVA); the intraocular pressure; the presenting features; the management strategy; the final anatomical and visual outcomes; and the cause(s) of poor outcome.

The eyes with no or minimal VH were carefully screened for the presence of retinal break(s). These breaks were immediately treated with either laser photocoagulation or cryotherapy. B-scan ultrasound was done in case the media clarity was poor. The eyes presenting with significant $\mathrm{VH}$ precluding the retinal view and/or RRD underwent $23 \mathrm{G}$ pars plana vitrectomy within 1 week of presentation. During the surgery, posterior vitreous detachment was induced. Complete removal of the posterior hyaloid was ensured with the help of intravitreal triamcinolone acetonide. Internal limiting membrane was peeled for about 2 disc-diameter on each side of the fovea in all the cases. The type of tamponade, $20 \%$ sulfur hexafluoride or 1000 centistokes silicone oil, was decided based on the retinal findings.

The patients were divided into three groups. Group 1 included the patients which presented with a clear media and no RRD; group 2 included the patients which presented with significant VH precluding the retinal view without RRD; while group 3 included the patients which presented with RRD with or without VH. The patients lost to follow-up before 6 months were excluded from the study (Fig. 1).

The anatomical and visual outcomes in each group were analyzed. The correlations between age, sex, ocular laterality, AL, the time of recognition of the inadvertent perforation, the number of retinal perforation(s), the anteroposterior and quadrant-wise location of the break(s) with the various types of complications, and the final visual outcome were also analyzed.

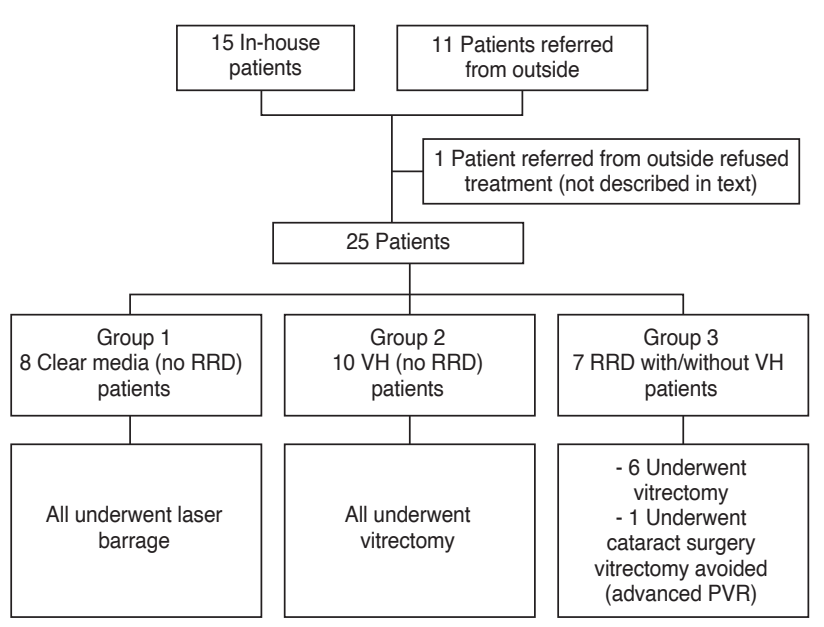

Fig. 1. Flowchart representing the number of patients who were treated for inadvertent ocular perforation during peribulbar and retrobulbar anesthesia. $\mathrm{RRD}=$ rhegmatogenous retinal detachment; $\mathrm{VH}=$ Vitreous hemorrhage; $\mathrm{PVR}=$ proliferative vitreoretinopathy changes. 


\section{Statistical analysis}

The statistical analysis was performed using Stata ver. 11.1 (Stata Corp., College Station, TX, USA). The continuous variables were expressed as mean \pm standard deviation while the categorical variables were expressed as percentages. The comparison between the categorical data was performed using the chi-square or Fisher exact test, while the difference in the continuous data was measured using the Student $t$-test or Mann-Whitney $U$-test. A two-tailed $p$-value less than 0.05 was considered to be statistically significant.

\section{Results}

Using the electronic medical record, we identified 26 patients who were diagnosed to have an accidental globe perforation while injecting either peribulbar or retrobulbar anesthesia. One patient, who was referred from outside the hospital, refused treatment and has not been described in the further text. The mean age of these 13 males and $12 \mathrm{fe}$ males was $59.2 \pm 11.0$ years (range, $36-72$ years). Out of the 25 patients ( 25 eyes) who received treatment, ten patients were referred from outside, while 15 patients had an in-house complication (Fig. 1). Thus, the incidence of an accidental in-house globe perforation was $0.002 \%$ (15 of 595,052). All the in-house accidental globe perforations were secondary to peribulbar block. However, we are not sure if the patients referred from outside received a peribulbar or a retrobulbar block. The mean AL was 24.7 $\pm 2.7 \mathrm{~mm}$ (range, $20.9-31.2 \mathrm{~mm}$ ). Eleven eyes (45.8\%) had an $\mathrm{AL} \geq 24 \mathrm{~mm}$ while six eyes (24.0\%) had an $\mathrm{AL} \geq 26$ $\mathrm{mm}$.

The accidental perforation was recognized at the time of performing the block in only nine patients $(36.0 \%)$, out of which seven patients $(92.0 \%)$ underwent the planned surgery at the same time (Table 1). The surgery was deferred in the other two patients $(8.0 \%)$. The patients who underwent the planned surgery despite the accidental perforation (recognized or unrecognized) did not develop any intraoperative complication(s).

The most common presenting features were VH $(\mathrm{n}=14$, $56.0 \%$ ), ocular hypotony ( $\mathrm{n}=7,28.0 \%)$, RRD $(\mathrm{n}=7$, $28.0 \%)$, and hyphema $(\mathrm{n}=2,8.0 \%)$. Endophthalmitis was not noted in any case. The treatment included laser photocoagulation or cryotherapy for the retinal break(s) $(n=7$, $28.0 \%)$ and pars plana vitrectomy $(\mathrm{n}=17,68.0 \%)$. One patient referred from outside presented to us 3 months after the incident. The surgeon had recognized the accidental perforation at the time of the block and had postponed the cataract surgery. At the time of presentation to Aravind Eye Hospital, Madurai, he had a dense cataract and total retinal detachment (RD) on B-scan ultrasound. He underwent cataract surgery, but vitrectomy was avoided because of advanced proliferative vitreoretinopathy changes and the expected poor prognosis.

Retinal breaks were identified (before or during surgery) in all the eyes (total 37 breaks), out of which two eyes had three breaks each and eight eyes had two breaks each (Fig. 2A, 2B, 3A-3D, 4A, 4B). Other complications (recognized after vitrectomy) included full-thickness macular hole $(\mathrm{n}=$

Table 1. Comparison of the time of recognition of the accidental globe perforation among the in-house and the patients referred from outside

\begin{tabular}{lcc}
\hline Variable & In-house perforation $(\mathrm{n}=15)$ & Patients referred from outside $(\mathrm{n}=10)$ \\
\hline Planned surgery before which the perforation happened & 13 & 10 \\
$\quad$ Cataract surgery & 1 & - \\
Penetrating keratoplasty & 1 & - \\
Silicone oil removal & $8(53.3)$ & $1(10.0)$ \\
Perforation recognized at the time of block & 1 & 1 \\
Surgery postponed after the perforation was recognized & $6(40.0)$ & $8(80.0)$ \\
Perforation recognized on postoperative day 1 & $1(6.7)^{*}$ & $1(10.0)$ \\
Perforation recognized within the first month &
\end{tabular}

Values are presented as number or number (\%); Only the patients who underwent treatment have been included.

"Penetrating keratoplasty. 
A

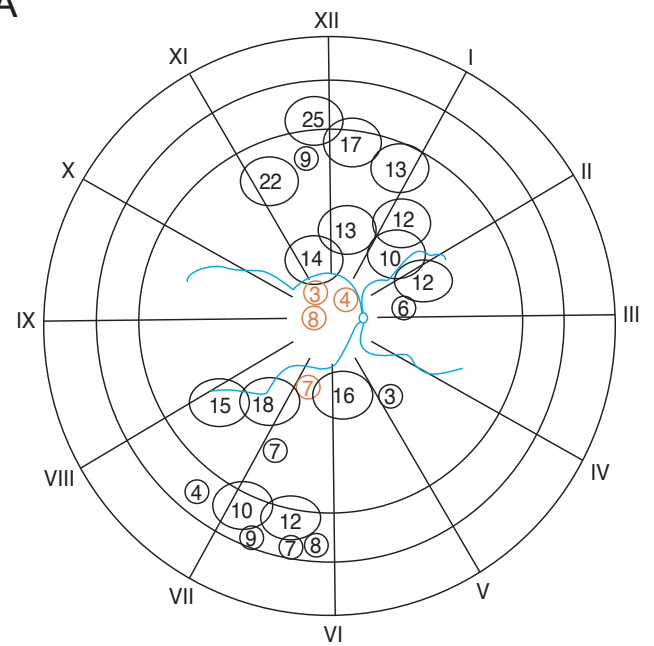

B

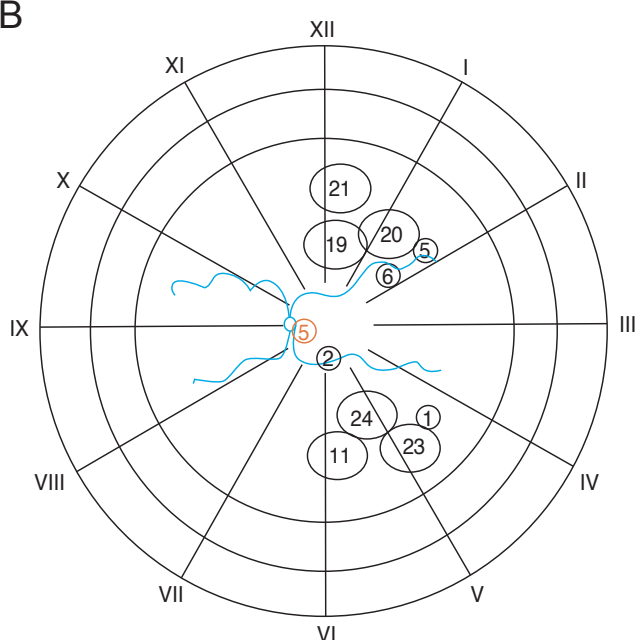

Fig. 2. Bjerrum chart showing the location of all the perforation sites in each patient in their respective (A) right eye and (B) left eye (black circle, entry wound; red circle, exit wound).

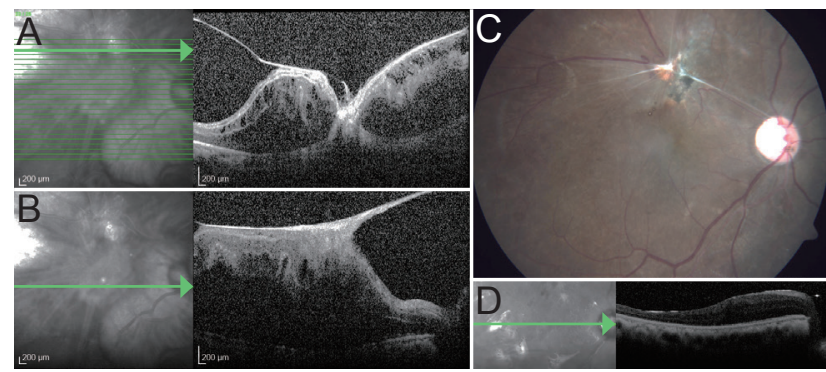

Fig. 3. Images of patient 14. Optical coherence tomography line scans at presentation through (A) the site of perforation and (B) fovea showing macular pucker. (C) Fundus image after silicone oil removal showing the site of perforation with a healthy macula. (D) Optical coherence tomography line scan after vitrectomy and silicone oil tamponade showing a settled macula with no epiretinal membrane. A written informed consent for publication of the clinical images was obtained from the patient.
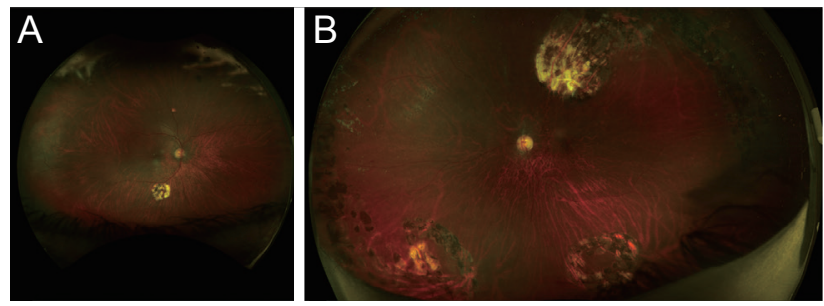

Fig. 4. Ultrawide field images (Optomap Panoramic 200 Standard imaging system; Optos, Dunfermline, UK) taken after silicone oil removal of (A) patient 15 showing lasered site of perforation in the inferotemporal quadrant and (B) patient 19 showing lasered breaks in the inferior half (original retinal detachment surgery) and lasered site of perforation in the superotemporal quadrant. Patient 19 had inadvertent perforation at the time of silicone oil removal. Written informed consents for publication of the clinical images were obtained from the patients.
5, 20\%), SRH $(n=4,16 \%)$, retinal necrosis $(n=3,12 \%)$, central retinal artery occlusion $(n=2,8 \%)$, branch retinal artery occlusion $(\mathrm{n}=1,4 \%)$ and central retinal vein occlusion $(n=1,4 \%)$.

Group 1 included eight patients. All the patients underwent laser barrage, except for the one who was planned to undergo silicone oil removal (SOR) at the time of the accidental perforation. He underwent endolaser during SOR. The mean presenting BCVA of the patients in this group was logarithm of the minimum angle of resolution (logMAR) $0.79 \pm 0.73$ (Snellen equivalent, 20 / 123), while the mean final BCVA was $\log$ MAR $0.59 \pm 0.79$ (Snellen equivalent, $20 / 78$ ) (Table 2). Group 2 included ten patients. All the patients underwent vitrectomy. The mean presenting BCVA of the patients in this group was logMAR $1.82 \pm$ 0.78 (Snellen equivalent, $20 / 1,321$ ), which improved to $\log$ MAR $0.61 \pm 0.20$ (Snellen equivalent, 20 / 81) after the treatment (Table 3). Group 3 included seven patients. All the patients underwent vitrectomy. The mean presenting BCVA was of the patients in this group logMAR $2.13 \pm$ 0.59 (Snellen equivalent, $20 / 2,698$ ), which improved to $\log$ MAR $1.25 \pm 0.64$ (Snellen equivalent, 20 / 356) after the treatment. Two patients in group 3 had a final BCVA $\leq 20$ / 1,200 , the causes which were central retinal artery occlusion and a failed Penetrating keratoplasty graft (Table 4).

All the eyes which received postoperative silicone oil tamponade underwent SOR. The retina remained attached 
Table 2. Demographic and clinical feature of the patients who presented with a clear media (group 1)

\begin{tabular}{|c|c|c|c|c|c|c|c|c|}
\hline $\begin{array}{l}\text { Patient } \\
\text { no. }\end{array}$ & $\begin{array}{l}\text { Age } \\
(\mathrm{yr})\end{array}$ & Sex & $\begin{array}{l}\text { Initial } \\
\text { BCVA }\end{array}$ & $\begin{array}{l}\text { Axial } \\
\text { length }\end{array}$ & Complications & Management & $\begin{array}{l}\text { Anatomical } \\
\text { outcome }\end{array}$ & $\begin{array}{c}\text { Final } \\
\text { BCVA }\end{array}$ \\
\hline 13 & 65 & Male & $20 / 20$ & 24.15 & Retinal break, hypotony & Laser photocoagulation & Attached retina & $20 / 20$ \\
\hline 16 & 47 & Female & $20 / 60$ & 23.56 & Retinal break, hypotony & Laser photocoagulation & Attached retina & $20 / 60$ \\
\hline 17 & 65 & Female & $20 / 200$ & 23.09 & Retinal break, hypotony & Laser photocoagulation & Attached retina & $20 / 80$ \\
\hline 19 & 49 & Male & $20 / 300$ & 23.89 & Retinal break, hypotony & Laser photocoagulation ${ }^{*}$ & Attached retina & $20 / 80$ \\
\hline 20 & 60 & Male & $20 / 120$ & 23.84 & Retinal break, hypotony & Laser photocoagulation & Attached retina & $20 / 40$ \\
\hline 21 & 58 & Female & $20 / 40$ & 23.24 & Retinal break, hypotony & Laser photocoagulation & Attached retina & $20 / 20$ \\
\hline 24 & 70 & Male & $\begin{array}{l}\text { Finger } \\
\text { counting }\end{array}$ & 22.93 & $\begin{array}{l}\text { Retinal break, central } \\
\text { retinal artery occlusion }\end{array}$ & Laser photocoagulation & Attached retina & $\begin{array}{l}\text { Finger } \\
\text { counting }\end{array}$ \\
\hline 25 & 47 & Female & $20 / 60$ & 23.47 & Retinal break, hypotony & Laser photocoagulation & Attached retina & $20 / 60$ \\
\hline
\end{tabular}

$\mathrm{BCVA}=$ best-corrected visual acuity.

*Planned for silicone oil removal with drainage implant, underwent additional endolaser.

Table 3. Demographic and clinical feature of the patients who presented with vitreous hemorrhage but no retinal detachment (group 2)

\begin{tabular}{|c|c|c|c|c|c|c|c|c|}
\hline $\begin{array}{l}\text { Patient } \\
\text { no. }\end{array}$ & $\begin{array}{l}\text { Age } \\
(\mathrm{yr})\end{array}$ & Sex & Initial BCVA & $\begin{array}{l}\text { Axial } \\
\text { length }\end{array}$ & Complications & Management & $\begin{array}{l}\text { Anatomical } \\
\text { outcome }\end{array}$ & $\begin{array}{l}\text { Final } \\
\text { BCVA }\end{array}$ \\
\hline 1 & 65 & Male & Hand movement & 23.80 & Retinal break & Vitrectomy, endolaser, SO & Attached retina & $20 / 60$ \\
\hline 2 & 80 & Male & Perception of light + & 24.06 & $\begin{array}{l}\text { Retinal break, } \\
\text { subretinal hemorrhage }\end{array}$ & Vitrectomy, endolaser, SO & Attached retina & $20 / 120$ \\
\hline 4 & 60 & Male & $20 / 400$ & 21.50 & $\begin{array}{l}\text { Retinal break, } \\
\text { subretinal hemorrhage }\end{array}$ & Vitrectomy, endolaser, SO & Attached retina & $20 / 120$ \\
\hline 6 & 55 & Male & $20 / 200$ & 29.37 & Retinal break & Vitrectomy, endolaser, SO & Attached retina & $20 / 40$ \\
\hline 7 & 60 & Female & Finger counting & 29.04 & Retinal break, FTMH & Vitrectomy, endolaser, SO & Attached retina & $20 / 120$ \\
\hline 8 & 65 & Female & $20 / 1,200$ & 23.68 & Retinal break, FTMH & Vitrectomy, endolaser, SO & Attached retina & $20 / 120$ \\
\hline 9 & 55 & Male & Perception of light + & 21.54 & $\begin{array}{l}\text { Retinal break, central } \\
\text { retinal vein occlusion }\end{array}$ & Vitrectomy, endolaser, SO & Attached retina & $20 / 80$ \\
\hline 14 & 50 & Male & $20 / 1,200$ & 20.90 & $\begin{array}{l}\text { Retinal break, macular } \\
\text { pucker }\end{array}$ & Vitrectomy, endolaser, SO & Attached retina & $20 / 120$ \\
\hline 15 & 75 & Male & $20 / 2,400$ & 22.96 & Retinal break & Vitrectomy, endolaser, SF6 & Attached retina & $20 / 40$ \\
\hline 23 & 71 & Female & $20 / 800$ & 22.77 & Retinal break & Vitrectomy, endolaser, SF6 & Attached retina & $20 / 60$ \\
\hline
\end{tabular}

$\mathrm{BCVA}=$ best-corrected visual acuity; FTMH = full-thickness macular hole; SO = silicone oil; SF6 = sulfur hexafluoride.

in all the eyes at the point of the last follow-up.

The age, sex, ocular laterality, the location of the perforation, and the number of perforations were similar were in all three groups; while the AL was significantly larger in group 3. Most of the eyes where the accidental perforation was not recognized at the same time developed complications like RRD and VH (i.e., groups 2 and 3). The incidence of vascular events was similar in all three groups. The initial and final BCVA was best in group 1 and worst in group 3 (Table 5).

Univariate analysis showed the development of RRD was associated with a larger $\operatorname{AL}(p=0.015)$, while the development of significant $\mathrm{VH}$ precluding retinal view was associated with the superior location of the perforation ( $p$ $=0.015)$, late recognition of the perforation $(p=0.004)$, and $>1$ perforations $(p=0.015)$. However, multivariate analysis showed that the difference was not statistically significant in any case. Univariate and multivariate analy- 
Table 4. Demographic and clinical feature of the patients presented with rhegmatogenous retinal detachment with or without VH (group 3)

\begin{tabular}{|c|c|c|c|c|c|c|c|c|}
\hline $\begin{array}{l}\text { Patient } \\
\text { no. }\end{array}$ & $\begin{array}{l}\text { Age } \\
(\mathrm{yr})\end{array}$ & Sex & Initial BCVA & $\begin{array}{l}\text { Axial } \\
\text { length }\end{array}$ & Complications & Management & $\begin{array}{l}\text { Anatomical } \\
\text { outcome }\end{array}$ & Final BCVA \\
\hline 3 & 60 & Female & Hand movement & 25.77 & $\begin{array}{l}\text { VH, retinal break, subretinal } \\
\text { hemorrhage, FTMH }\end{array}$ & $\begin{array}{l}\text { Vitrectomy, } \\
\text { endolaser, SO }\end{array}$ & Attached retina & $20 / 1,200$ \\
\hline 5 & 55 & Female & Perception of light + & 26.89 & $\begin{array}{l}\text { VH, retinal break, subretinal } \\
\text { hemorrhage, FTMH }\end{array}$ & $\begin{array}{l}\text { Vitrectomy, } \\
\text { endolaser, SO }\end{array}$ & Attached retina & $20 / 120$ \\
\hline 10 & 72 & Female & $20 / 400$ & 24.30 & VH, retinal break, IT-BRAO & $\begin{array}{l}\text { Vitrectomy, } \\
\text { endolaser, SO }\end{array}$ & Attached retina & $20 / 120$ \\
\hline 11 & 42 & Male & $20 / 200$ & 31.22 & VH, Retinal break, hypotony & $\begin{array}{l}\text { Vitrectomy, } \\
\text { endolaser, SO }\end{array}$ & Attached retina & $20 / 120$ \\
\hline 12 & 46 & Male & Finger counting & 29.59 & $\begin{array}{l}\text { VH, Retinal break, FTMH, } \\
\text { retinal necrosis }\end{array}$ & $\begin{array}{l}\text { Vitrectomy, } \\
\text { endolaser, SO }\end{array}$ & Attached retina & $20 / 240$ \\
\hline 18 & 36 & Female & $20 / 1,200$ & 24.18 & Retinal break & $\begin{array}{l}\text { Vitrectomy, } \\
\text { endolaser, SO }\end{array}$ & Attached retina & $\begin{array}{l}\text { Finger } \\
\text { counting }\end{array}$ \\
\hline 22 & 71 & Female & Perception of light + & 26.89 & Retinal break & $\begin{array}{l}\text { Treatment not } \\
\text { taken }^{*}\end{array}$ & $\begin{array}{l}\text { Retinal } \\
\text { detachment }\end{array}$ & $\begin{array}{l}\text { Perception of } \\
\text { ligh }+\end{array}$ \\
\hline
\end{tabular}

$\mathrm{VH}=$ vitreous hemorrhage; $\mathrm{BCVA}=$ best-corrected visual acuity; FTMH = full-thickness macular hole; $\mathrm{SO}=$ silicone oil; IT-BRAO = infero-temporal branch retinal artery occlusion.

*Vitrectomy avoided because of advanced proliferative vitreoretinopathy changes and poor visual prognosis.

Table 5. Comparison of baseline features and outcome among the three groups

\begin{tabular}{|c|c|c|c|c|}
\hline Variable & Group 1 & Group 2 & Group 3 & $p$-value \\
\hline No. of patients & $8(32.0)$ & $10(40.0)$ & $7(28.0)$ & \\
\hline Age $(y r)$ & $57.6 \pm 9.0$ & $63.6 \pm 9.5$ & $54.6 \pm 14.0$ & $0.233^{\dagger}$ \\
\hline Sex (female : male) & $4: 4$ & $3: 7$ & $5: 2$ & 0.280 \\
\hline Ocular laterality (right : left) & $3: 5$ & $7: 3$ & $4: 3$ & 0.366 \\
\hline Axial length (mm) & $23.5 \pm 0.4$ & $24.0 \pm 3.0$ & $26.9 \pm 2.6$ & $0.021^{\dagger}$ \\
\hline $\begin{array}{l}\text { No. of eyes where perforation was recognized at the time of } \\
\text { anesthesia }\end{array}$ & $7(87.5)$ & $0(0.0)$ & $2(28.6)$ & $<0.001$ \\
\hline Clockwise location of perforation (inferior half : superior half) & $2: 6$ & $8: 2$ & $4: 5$ & 0.073 \\
\hline No. of eyes with perforation inside the posterior pole & $0(0.0)$ & $3(30.0)$ & $2(28.6)$ & 0.265 \\
\hline No. of eyes with $>1$ perforations & $1(12.5)$ & $5(50.0)$ & $4(57.1)$ & 0.159 \\
\hline No. of eyes with vascular event & $1(12.5)$ & $1(10.0)$ & $2(28.3)$ & 0.646 \\
\hline Median initial BCVA & & & & 0.009 \\
\hline $\log M A R$ & 0.63 & 1.78 & 2.30 & \\
\hline Snellen equivalent & $20 / 85$ & $20 / 1,205$ & $20 / 3,991$ & \\
\hline Median final BCVA & & & & $0.006^{+}$ \\
\hline $\log M A R$ & 0.48 & 0.69 & 1.08 & \\
\hline Snellen equivalent & $20 / 60$ & $20 / 98$ & $20 / 240$ & \\
\hline
\end{tabular}

Values are presented as number (\%), number, or mean \pm standard deviation.

$\mathrm{BCVA}=$ best-corrected visual acuity; $\operatorname{logMAR}=$ logarithm of the minimum angle of resolution.

${ }^{*}$ Fisher exact test; ${ }^{\dagger}$ ANOVA test; ${ }^{\dagger}$ Kruskal-Wallis test. 
ses showed that the incidence of the vascular events was not associated with either age, sex, ocular laterality, the location of the perforation, the number of perforations, or AL. Univariate $(p=0.005)$ and multivariate analyses $(p=$ 0.014) showed that the final BCVA depended only on the initial BCVA.

\section{Discussion}

Accidental scleral perforation is one of the rarest yet the most devastating complication of local ocular anesthesia [1-3]. The incidence is higher in the case of the blocks is injected in the retrobulbar space compared to peribulbar space $[1,2,4-6,19,20]$. The incidence of accidental globe perforation in this study was similar to that reported in the literature. The risk factors for such an event include posterior staphyloma, long $\mathrm{AL}$, uncooperative patient, multiple attempts, and inexperienced personnel administering the block [5,10-14,19-23]. We believe that a combination of these factors was responsible for the accidental globe perforation in our series. Nearly one-half of the eyes in our series had an AL $>24 \mathrm{~mm}$, while nearly one-fourth of eyes had an AL $>26 \mathrm{~mm}$. However, the data related to the clinical experience of the person administering the block and the number of attempts taken to achieve adequate anesthesia were not available.

The early indicators of globe perforation include the movement of eyeball along with the movement of the anesthetic syringe needle, unusual difficulty while injecting, severe pain response of the patient, sudden intraocular pressure rise or severe hypotony, corneal clouding, change in the ocular red reflex, sudden visual loss, visible enlargement of the eyeball, and/ or a popping sound [4,6,7,20,24]. However, it is not always easy to identify the perforation at the time of injection. In our case series, $50 \%$ of the inhouse perforations were identified at the time of injection, while others were recognized on postoperative day 1. Other authors have also reported that only $0 \%$ to $53 \%$ of perforations are recognized at the time of surgery $[8,9,12,20,22,23,25]$.

Early management remains controversial. While some authors advocate postponing the planned surgery, others recommend proceeding with the same. We believe that it is better to proceed with the surgery in case the cataract is dense as this will help in early diagnosis and treatment of the vitreoretinal complication(s). There are no reported contraindications for the placement of an intraocular lens in such eyes [8,9,14,23-25]. Most patients in our case series also underwent the planned surgery even after the accidental perforation (recognized or unrecognized) and did not develop any intraoperative complication(s).

A vitreoretinal surgeon's opinion should be sought as early as possible. We found that the eyes where the inadvertent perforation was recognized at the same time did not develop complications like RRD or VH. In case the media is clear, a thorough search for a retinal break(s) should be done. It should be kept in mind that more than one break may be present [25]. In our study nearly $40 \%$ of eyes had more than one retinal break. In the absence of other complications, treating these retinal breaks leads to a good outcome. In our study, all the patients in group 1 maintained good vision except for one patient who developed central retinal artery occlusion. None of the eyes progressed to RRD. However, it is imperative to mention that these patients need to be followed up closely as subretinal fluid can accumulate over some time.

The presence of $\mathrm{VH}$ with or without RRD warrants an immediate vitrectomy as proliferative vitreoretinopathy changes may develop aggressively $[4,6,8,10,12-15,19,20,23$ 25]. One patient in our series presented 3 months after the accidental perforation. The eye had developed advanced proliferative vitreoretinopathy and could not undergo vitrectomy. Early surgery in the other patients led to $100 \%$ anatomical success. The anatomical and visual outcomes in our case series were better than reported earlier [8,21$23,25]$. Previous studies have reported that RD may recur in $16 \%$ to $43 \%$ of cases $[8,14,20,22-25]$. However, in our case series, the retina remained attached in all the eyes even after the tamponade was removed. Table 6 provides a brief comparison of the results of our study vis-a-vis the earlier ones [8,19,20,22-25]. The better outcomes in our study can be attributed to early recognition of the perforation and its associated complications and early treatment, as well as the recent technological improvement in vitreoretinal surgeries.

We preferred to peel internal limiting membrane in all the cases because of its multiple advantages. It ensures complete removal of the posterior hyaloid. This is especially important in these eyes as they are commonly associated with vitreoschisis, which makes intraoperative identification and complete removal of the posterior hyaloid 


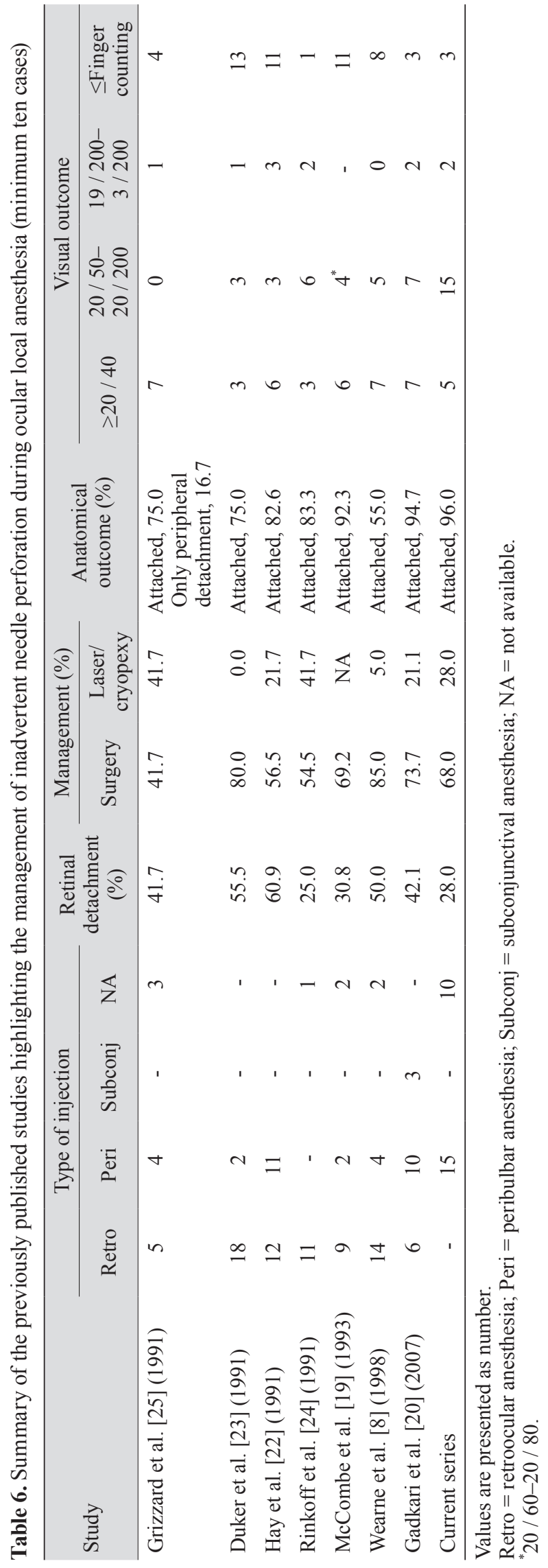

difficult, thus compromising the surgical outcome [26]. It also reduces the chances of postoperative epiretinal membrane formation and retinal re-detachment [27-31].

More than $50 \%$ of eyes in our series achieved final BCVA $\geq 20 / 80$ while $25 \%$ of eyes achieved BCVA between $20 / 120$ to $20 / 200$. The causes for suboptimal visual gain were the development of RRD, vascular occlusion, and macular pathologies like full-thickness macular hole, $\mathrm{SRH}$, and macular pucker. As reported in the literature, we also observed that the patients with RRD had a worse visual outcome than those without RRD [21-23]. Hay et al. [22] reported that final BCVA $\geq 20 / 400$ was achieved in only $14.3 \%$ of patients with RD. Duker et al. [23] reported that final BCVA $\geq 20 / 400$ was achieved in only $9.1 \%$ patients with RD. Wearne et al. [8] reported $78 \%$ eyes had final $\mathrm{BCVA} \leq$ finger counting. However, the results in our case series were better as nearly $40 \%$ of patients achieved a final $B C V A \geq 20 / 200$.

The reported causes of poor vision in eyes without RRD include epiretinal membrane formation, needle injury to the macula or the maculopapular bundle, optic atrophy, macular SRH, persistent hemorrhagic choroidal detachment, and vascular occlusion [32-37]. The incidence of retinal vascular occlusion, SRH, full-thickness macular hole, and macular pucker in our study was $12 \%, 16 \%, 20 \%$, and $4 \%$ respectively. There were no cases of hemorrhagic choroidal detachment in our series. Retinal vascular occlusion may be caused if the anesthetic agent is inadvertently injected inside the globe, causing a sudden rise of intraocular pressure. This phenomenon is popularly known as an ocular explosion [7,8]. Even in the case of an accidental scleral perforation, utmost care should be taken to avoid intraocular injection of the anesthetic agent as it can lead to mechanical as well as chemical damage.

In addition, we found that the myopic eyes were at a higher risk of developing RRD. This predisposition may be because myopic eyes are associated with degenerated vitreous, thinner retina, and a high incidence of peripheral retinal degenerations [38-40]. Further, superior location of the perforation and multiple perforations predisposed the eyes to significant $\mathrm{VH}$ precluding retinal view. Other authors have also reported that retinal break(s) in the eyes with posterior vitreous detachment-induced dense fundus-obscuring VH are mostly located in the superior retina $[41,42]$. The vascular complications did not depend on AL, location of the perforation, or the number of perforation(s). 
It probably occurs secondary to the accidental injection of the anesthetic agent inside the eyeball [7].

To the best of our knowledge, this is the largest series that evaluated the risk factors for the development of secondary complications and the management of eyes that had an inadvertent scleral perforation while administrating peribulbar or retrobulbar block. The uniformity in the treatment protocol forms one of the strengths of the study. However, the study is limited by its retrospective nature, small sample size, and unavailability of the data related to the clinical experience of the person administrating the anesthesia blocks.

Our study shows that early recognition and intervention in patients with an inadvertent globe perforation can lead to a good outcome. Eyes with longer AL, superior, and multiple perforations are at higher risk of developing complications like RRD and VH. Risk factors for poor outcome include the development of secondary complications like retinal vascular occlusion, macular injury, and RRD.

\section{Conflicts of Interest}

No potential conflict of interest relevant to this article was reported.

\section{Acknowledgements}

None.

\section{Funding}

The authors received no financial support for this article.

\section{References}

1. Eke T, Thompson JR. Serious complications of local anaesthesia for cataract surgery: a 1 year national survey in the United Kingdom. Br J Ophthalmol 2007;91:470-5.

2. Lee RM, Thompson JR, Eke T. Severe adverse events associated with local anaesthesia in cataract surgery: 1 year national survey of practice and complications in the UK. $\mathrm{Br} J$ Ophthalmol 2016;100:772-6.
3. Ginsburg RN, Duker JS. Globe perforation associated with retrobulbar and peribulbar anesthesia. Semin Ophthalmol 1993;8:87-95.

4. Rosenthal G, Bartz-Schmidt KU, Engels B, et al. Primary use of silicone oil tamponade in the management of perforating globe injury secondary to inadvertent local anaesthesia injection for ophthalmic surgery. Int Ophthalmol 1997-1998;21:349-52.

5. Edge R, Navon S. Scleral perforation during retrobulbar and peribulbar anesthesia: risk factors and outcome in 50,000 consecutive injections. J Cataract Refract Surg 1999;25:1237-44.

6. Kimble JA, Morris RE, Witherspoon CD, Feist RM. Globe perforation from peribulbar injection. Arch Ophthalmol 1987;105:749.

7. Brar GS, Ram J, Dogra MR, et al. Ocular explosion after peribulbar anesthesia. $J$ Cataract Refract Surg 2002;28:55661.

8. Wearne MJ, Flaxel CJ, Gray P, et al. Vitreoretinal surgery after inadvertent globe penetration during local ocular anesthesia. Ophthalmology 1998;105:371-6.

9. Puri P, Verma D, McKibbin M. Management of ocular perforations resulting from peribulbar anaesthesia. Indian $J$ Ophthalmol 1999;47:181-3.

10. Gopal L, Badrinath SS, Parikh S, Chawla G. Retinal detachment secondary to ocular perforation during retrobulbar anaesthesia. Indian J Ophthalmol 1995;43:13-5.

11. Ball JL, Woon WH, Smith S. Globe perforation by the second peribulbar injection. Eye (Lond) 2002;16:663-5.

12. Gillow JT, Aggarwal RK, Kirkby GR. Ocular perforation during peribulbar anaesthesia. Eye (Lond) 1996;10 (Pt 5):533-6.

13. Slaughter K, Lee L. Globe perforation following peribulbar injection. Clin Exp Ophthalmol 2003;31:265-7.

14. Modarres M, Parvaresh MM, Hashemi M, Peyman GA. Inadvertent globe perforation during retrobulbar injection in high myopes. Int Ophthalmol 1997-1998;21:179-85.

15. Schneider ME, Milstein DE, Oyakawa RT, et al. Ocular perforation from a retrobulbar injection. Am J Ophthalmol 1988;106:35-40.

16. Wadood AC, Dhillon B, Singh J. Inadvertent ocular perforation and intravitreal injection of an anesthetic agent during retrobulbar injection. $J$ Cataract Refract Surg 2002;28:562-5.

17. Lake D, Mearza A, Ionides A. Consequence of perforation during peribulbar anesthesia in an only eye. $J$ Cataract $R e$ - 
fract Surg 2003;29:2234-5.

18. Joseph JP, McHugh JD, Franks WA, Chignell AH. Perforation of the globe: a complication of peribulbar anaesthesia. Br J Ophthalmol 1991;75:504-5.

19. McCombe M, Heriot W. Penetrating ocular injury following local anaesthesia. Aust N Z J Ophthalmol 1995;23:33-6.

20. Gadkari SS. Evaluation of 19 cases of inadvertent globe perforation due to periocular injections. Indian J Ophthalmol 2007;55:103-7.

21. Schrader WF, Schargus M, Schneider E, Josifova T. Risks and sequelae of scleral perforation during peribulbar or retrobulbar anesthesia. J Cataract Refract Surg 2010;36:885-9.

22. Hay A, Flynn HW Jr, Hoffman JI, Rivera AH. Needle penetration of the globe during retrobulbar and peribulbar injections. Ophthalmology 1991;98:1017-24.

23. Duker JS, Belmont JB, Benson WE, et al. Inadvertent globe perforation during retrobulbar and peribulbar anesthesia: patient characteristics, surgical management, and visual outcome. Ophthalmology 1991;98:519-26.

24. Rinkoff JS, Doft BH, Lobes LA. Management of ocular penetration from injection of local anesthesia preceding cataract surgery. Arch Ophthalmol 1991;109:1421-5.

25. Grizzard WS, Kirk NM, Pavan PR, et al. Perforating ocular injuries caused by anesthesia personnel. Ophthalmology 1991;98:1011-6.

26. Sebag J. Anomalous posterior vitreous detachment: a unifying concept in vitreo-retinal disease. Graefes Arch Clin Exp Ophthalmol 2004;242:690-8.

27. Sousa K, Calvao-Santos G, Costa J, et al. Anatomical and functional results of ILM peeling vs. non-peeling in macula-off rhegmatogenous retinal detachment. Graefes Arch Clin Exp Ophthalmol 2020;258:2105-10.

28. Kumar V, Dubey D, Kumawat D, et al. Role of internal limiting membrane peeling in the prevention of epiretinal membrane formation following vitrectomy for retinal detachment: a randomised trial. Br J Ophthalmol 2020;104:1271-6.

29. Forlini M, Date P, Ferrari LM, et al. Comparative analysis of retinal reattachment surgery with or without internal limiting membrane peeling to prevent postoperative macular pucker. Retina 2018;38:1770-6.

30. Akiyama K, Fujinami K, Watanabe K, et al. Internal limiting membrane peeling to prevent post-vitrectomy epiretinal membrane development in retinal detachment. Am J Ophthalmol 2016;171:1-10.

31. Bawankule PK, Narnaware SH, Raje DV, Chakraborty M. Internal limiting membrane peel: does it change the success rate of primary vitrectomy without belt buckle in rhegmatogenous retinal detachments? Indian J Ophthalmol 2019;67:1448-54.

32. Naik AA, Agrawal SA, Navadiya ID, Ramchandani SJ. Management of macular epiretinal membrane secondary to accidental globe perforation during retrobulbar anesthesia. Indian J Ophthalmol 2014;62:94-5.

33. Shukla D. Management of macular epiretinal membrane secondary to accidental globe perforation during retrobulbar anesthesia. Indian J Ophthalmol 2013;61:234-5.

34. Bloch E, Malik M, Bhardwaj G, Scott A. Scleral perforation involving the papillomacular bundle secondary to peribulbar anaesthetic injection. Am J Ophthalmol Case Rep 2020;18:100657.

35. Al-Shehri A, Al-Ghamdi A, Al-Shehri A, Alakeely A. Management of iatrogenic globe perforation during peribulbar anesthesia with submacular hemorrhage. Oman J Ophthalmol 2020;13:95-7.

36. Dikci S, Yilmaz T, Gok ZE, et al. Choroidal neovascularization secondary to ocular penetration during retrobulbar anesthesia and its treatment. Oman J Ophthalmol 2017;10:44-6.

37. Dubey D, Shanmugam M, Ramanjulu R, et al. Swept source optical coherence tomography in globe perforation. Indian J Ophthalmol 2019;67:1697-8.

38. Akiba J. Prevalence of posterior vitreous detachment in high myopia. Ophthalmology 1993;100:1384-8.

39. Jonas JB, Xu L, Wei WB, et al. Retinal thickness and axial length. Invest Ophthalmol Vis Sci 2016;57:1791-7.

40. Morita H, Funata M, Tokoro T. A clinical study of the development of posterior vitreous detachment in high myopia. Retina 1995;15:117-24.

41. Sarrafizadeh R, Hassan TS, Ruby AJ, et al. Incidence of retinal detachment and visual outcome in eyes presenting with posterior vitreous separation and dense fundus-obscuring vitreous hemorrhage. Ophthalmology 2001;108:2273-8.

42. Seelenfreund MH, Sternberg I, Hirsch I, Silverstone BZ. Retinal tears with total vitreous hemorrhage. Am J Ophthalmol 1983;95:659-62. 